\title{
OVERVIEW OF THE LAW AND AVAILABILITY OF ABORTION SERVICES IN GHANA
}

\author{
R.A.S MORHEE AND * E.S.K. MORHEE ${ }^{1}$ \\ Faculty of Law, Kwame Nkrumah University of Science and Technology, Kumasi, Ghana and ${ }^{1}$ De- \\ partment of Obstetrics and Gynaecology, Komfo Anokye Teaching Hospital, Kumasi, Ghana.
}

\begin{abstract}
SUMMARY
Introduction: In Ghana unsafe abortion remains a major public health problem despite apparent liberalization of the law on abortion over two decades. The contention is that the current law on abortion makes enforceability difficult and leaves room for untrained personnel to engage in dangerous abortion procedures and that there is need for law reform.

Objectives: To bring into focus how the current law affects the availability of safe abortion service in Ghana and to bring out suggestions that may be useful in future amendment of the law.

Methods: Using the information gathered from literature review the current law on abortion in Ghana and relevant sections of the criminal code were critically analyzed from medico-legal perspective.
\end{abstract}

Findings: Since 1985 the Ghanaian law on abortion has changed from its preoccupation with prohibition and punishment towards liberalization of abortion but there has been delay in policy formulation and implementation to translate the law into services. Hence safe abortion services on medicosocial grounds as permitted by the law are not readily available in national health institutions. Some aspects of the law still appear implicit and may hamper implementation of safe abortion service in the country.

Conclusion: For clarity there is need for more amendments in the law in order to regulate abortion and to enhance the right of the woman to make a choice on her own. There is also the need to expedite action on development policy and standard guidelines for practitioners.

Keywords: Unsafe Abortion, Legal abortion

\section{INTRODUCTION}

Unsafe abortion is a major public health problem in developing countries where abortion is restricted by laws which seek to prevent and punish

\footnotetext{
* Author for correspondence
}

this form of behaviour with the aim of preventing its occurrence and to deter people with like minds from indulging in such a practice. History however, shows that abortion is a fundamental human behaviour that has been practiced in all cultural settings and that no level of restrictive laws has succeeded in controlling it. ${ }^{1,2}$ Thus when a woman decides to end an unwanted pregnancy she will often go to extreme length to do so, regardless of whether the procedure is safe or legal and as long as there is unwanted pregnancy abortion will be a fact of life. Unsafe abortion accounts for at least $13 \%$ of global maternal mortality that is disproportionately high in Africa ${ }^{3,4}$ Most of these deaths as well as the long-term complications of unsafe abortion are preventable through improved access to effective family planning methods and contraception to reduce the incidence of unwanted pregnancy, post-abortion care and provision of safe abortion services. Besides the health complications of unsafe abortion the socioeconomic cost is so high that in some centres in developing countries, treating abortion-related complications may consume up to $50 \%$ of hospital budgets and resources, including medical staff time, medicines and supplies $^{5}$

Until the second half of the $20^{\text {th }}$ century abortion was illegal in most countries and was associated with high illegal and unsafe abortion rate and correspondently high maternal morbidity and mortality. ${ }^{6}$ Recent years have seen the liberalization of abortion laws in almost all countries of the European Union, the United States and Canada. This together with better and wide spread promotion and use of contraceptives led to rapid decline in the rate of unsafe abortion and its associated mortality in the developed world., ${ }^{2,7}$ It has been observed that in many developing countries safe abortion services are not available to the full extent permitted by law. In Ghana, despite the amendment of the law on abortion in 1985 to broaden the indications for legal abortion, unsafe abortion re- 
mains a major public problem and a leading cause of maternal deaths in the country. It also causes a significant morbidity among women in reproductive age. ${ }^{8,9}$

It is important to note that the translation of the law into services requires enabling policy formulation and implementation which in turn depend heavily on the clarity of the law. ${ }^{10}$ The contention however, is that the current law on abortion in Ghana makes enforceability difficult and leaves room for untrained personnel to engage in dangerous abortion procedures and that there is the necessity and pressing need for law reform. This overview is aimed at bringing into focus how the current law affects the availability of safe abortion service in Ghana and to make suggestions that may be useful in future amendment of the law.

\section{METHODS}

Extensive literature review was done by hand search of relevant books and journals and by electronic search from web sites on the internet using words like 'Abortion, policy and the law', 'Trend of abortion laws', 'unsafe abortion in Ghana', 'maternal mortality and abortion in Ghana'. Critical analysis of the law, as stated in the 1999 revised version of the Consolidated Criminal Code of the Republic of Ghana, 1960, Act 29 was made to find out how it promotes or hampers establishment of safe abortion units in the country. The current Ministry of Health Reproductive Health Policy on unsafe abortion was reviewed in relation to the law. Reference was made to the law on abortion in other jurisdictions particularly the current UK law since the original abortion law in Ghana was fundamentally based on the old British statute, 'the Offences against the Person Act of 1861'. Discussions were made based on the authors' understanding of the law as well as the World Health Organization recommendations on the provision of safe abortion and the global trend of liberalization of abortion laws. Other relevant sections of the criminal code are also discussed.

\section{RESULTS}

\section{The Current Law on Abortion in Ghana}

In Ghana abortion is a criminal offence regulated by Act 29, section 58 of the Criminal code of 1960, amended by PNDCL 102 of 1985 . It states that: ${ }^{11}$

1. Subject to the provisions of subsection (2) of this section

a. any woman who with intent to cause abortion or miscarriage administers to herself or consent to be administered to her any poison, drug or other noxious thing or uses any instrument or other means whatsoever; or

b. any person who-

(i) administers to a woman any poison, drug or other noxious thing or uses any instrument or other means whatsoever with intent to cause abortion or miscarriage, whether or not the woman is pregnant or has given her consent

(ii) induces a woman to cause or consent to causing abortion or miscarriage;

(iii) aids and abets a woman to cause abortion or miscarriage;

(iv) attempts to cause abortion or miscarriage; or

(v) supplies or procures any poison, drug, instrument or other thing knowing that it is intended to be used or employed to cause abortion or miscarriage; shall be guilty of an offence and liable on conviction to imprisonment for a term not exceeding five years.

2. It is not an offence under section (1) if an abortion or miscarriage is caused in any of the following circumstances by a registered medical practitioner specializing in Gynaecology or any other registered medical practitioner in a government hospital or a private hospital or clinic registered under the Private Hospital and Maternity Home Act, 1958 (No. 9) or in a place approved for the purpose by legislative instrument made by the Secretary:

a. where pregnancy is the result of rape or defilement of a female idiot or incest and the abortion or miscarriage is requested by the victim or her next of kin or the person in loco parentis, if she lacks the capacity to make such request;

b. where the continuance of the pregnancy would involve risk to the life of the pregnant woman or injury to her physical or mental health and such a woman consents to it or if she lacks the capacity to give such consent it is given on her behalf by her next of kin or the person in loco parentis;

c. where there is substantial risk that if the child were born it may suffer from or later develop a serious physical abnormality or disease. 
3. For the purposes of this section Abortion or miscarfitggarly,ethe pret takes the stance that human life mature expulsion or removal of conception from thebeginssatronocraption and seeks to protect the fetus. before the period of gestation is completed.

The Policy and Availability of Safe Abortion Service in Ghana

Over the years the reproductive health policy of Ghana on reduction of unsafe abortion only dwelt on promotion of family planning, contraception and post-abortion care but not provision of safe abortion within the confines of the law as recommended by World Health Organization ${ }^{12}$. However termination of pregnancy to save the mother's life in cases of serious medical conditions like hypertensive disorders, renal failure, etc. and obstetric emergencies like acute haemorrhage in pregnancy has been available in virtually all public and private hospitals in Ghana. Termination of pregnancy on medico-social grounds as indicated in the current law is, however, not readily available in national health institutions in the country. Such services are available in some private institutions especially in urban centres. As a result of illiteracy and social deprivation many women in Ghana do not know their legal rights to safe abortion. There is also anti-abortion social stigma and for many, safe abortion is cost-prohibitive since the service has been left in the hands of a few private practitioners who charge exorbitant fees. Consequently legal abortion is only available to wealthy and educated women. Thus although the law criminalises abortion but gave quite liberal grounds on which legal abortion may be permitted, unsafe abortion remains a major cause of maternal morbidity and mortality in Ghana ${ }^{13,8,14,15,9}$.

Following the inclusion of 'provision of abortion' in the reproductive health policy of December, 2003 the Ministry of Health has taken up the challenge to have the policy implemented within the confines of the current law and service protocols are in advanced stage of development.

\section{DISCUSSION}

The legal status of abortion is not necessarily the most important factor determining availability of safe abortion services. Other equally important factors include the national policy, the attitude of the health professionals, the public and sociocultural norms of the country. Considering the dire complications of unsafe abortion in Ghana, majority of doctors do not have negative attitude towards making abortion safe. Most medical practitioners in Ghana are aware of the law on abortion and most of them think that the law lacks clarity in some of its provisions ${ }^{16}$.
Thus according to the law once a woman conceives or becomes pregnant, the said pregnancy, right from conception till the foetus is born, cannot be terminated except under the stated circumstances.

\section{Definition of abortion or miscarriage}

The definition of abortion or miscarriage as stated in the Act seems to depart from the generally accepted medical definition of abortion as 'termination of pregnancy before viability', that is the gestational age at which the foetus is capable of surviving as an independent entity. Although a vague concept World Health Organization put viability at 24 weeks gestation and this has been used by most developed countries where abortion is permitted on wider grounds including socio-economic reasons or on request. In the West African sub-region viability has been pegged at gestational age of 28 weeks, from the last menstrual period. Hence, termination of pregnancy before 28 weeks is considered an abortion in West African countries including Ghana. It is however, important to note that the definition as given is for the purposes of the section 58 of criminal code which seeks to give protection to the foetus till the onset of labour when the gestation is presumed to have been completed. In labour the foetus is protected by sections 60 and 61 of the criminal code till the foetus is completely brought forth alive when he or she becomes a person (section 66). Thus the criminal code seems not to have offered the foetus the right of a person and seeks to indicate that personhood begins at the time of complete delivery of the foetus from the mother's body. This however, cannot be applied when the gestational age is less than six months whether the baby is born alive or dead. This may be an attempt by the criminal code to put viability at six months. Thus the body of babies brought forth at gestational age less than six months could be disposed of without committing an offence of concealment of the body or birth of a child [section 62 and 63 (3)]. However good clinical practice advocates that such babies be shown to the parents if they so wish. ${ }^{17}$ For clarity, there is the need to change the definition of 'abortion or miscarriage' in the Act to bring it in line with standard Obstetric definition.

\section{Gestational age limit}

In Obstetric practice pregnancy could be interrupted at any gestational age to save the woman's life. Thus the Ghanaian law seems to allow 'therapeutic abortion' and therefore sets no limit to the 
gestational age at which pregnancy could be lawfully terminated. In absence of appropriate policies on abortion this could be exploited by an abortionist to perform the procedure even in the advanced stages of pregnancy with very serious maternal complications. This allows the conclusion that Ghanaian law compared with similar legislations from other jurisdictions seems to be very flexible and gives abortionists a great deal of protection. It is clear that there may be the need to amend the law on abortion so as to set a limit to the gestational age at which safe abortion could be carried out. Inspiration could be drawn from the current British legislation in which legal abortion is only permitted before the $24^{\text {th }}$ week of amenorrhea except in some circumstances.

It is worth noting that as the law becomes more liberal safety of abortion becomes paramount and there would be the need to set a limit to the gestational age at which safe abortion may be permitted. There would therefore be the need for the medical and legal experts in the sub-region to take a look at the survival of preterm babies and the safety of late abortions, especially between 24-27 weeks so as to redefine viability for the sub-region in conformity with the existing laws and standard Obstetric practice as well as WHO definition of viability.

\section{Grounds on legal abortion}

The law acknowledges that there are certain circumstances under which abortion may be allowed or is legal. Critical analysis, however, indicates that of some of the permissive provisions in the law lack clarity with respect to offering safe abortion services in the country. For instance, that abortion may be permitted 'where the continuance of the pregnancy would involve risk to the life or physical and mental health of the pregnant woman, when viewed in broader perspectives raises a number of questions that leave doubt in the minds of medico-legal practitioners. Every pregnancy poses some risk to the health and the life of the woman. One then wonders what critical level of risk is being referred to in the Act at which such a crucial decision could be taken to terminate pregnancy. Although section 67 (2) of the criminal code stated that such a decision should be taken in good faith and without negligence, which presupposes that the decision should be in the best interest of the patient the provision is implicit and subject to variable interpretation and therefore leaves room for the abortionist to operate and may make it difficult for policy formulation and implementation. Of course, the land mark English case of R v.
Bourn has explained that the doctor must not wait until the mother is in danger of immediate death before he performs the procedure. It is enough if on reasonable grounds and with adequate knowledge and in good faith he comes to that decision. Hence abortion could be permitted where the continuance of the pregnancy would pose greater danger to the woman than termination of pregnancy. Thus in serious medical and obstetric complications the grounds for legal abortion is clear to most medical practitioners and as stated above such services are available in all public health institutions including mission hospitals in Ghana. Under such conditions the decision to terminate the pregnancy to save the mother's life is taken in good faith by the clinician responsible for the care of the woman and is taken with an informed consent of the woman as stated in section 67 (2) of the criminal code.

Again the law does not specify when a pregnancy could be said to be injurious to the physical and mental health of a woman neither does it explain what it means by physical and mental health, and therefore varying interpretation could be given. Threat to mental health could mean psychological distress caused by any factor that makes pregnancy difficult to carry. Some of the common factors found in Ghana include unstable relationship with the male partner, career development, poverty, lack of social support, the need to care for other young children in the family, health problems, the diagnosis of foetal abnormalities, fear of parents, and pregnancy as a result of rape or incest. ${ }^{15,18}$ Since the level of risk or the threat to the physical and mental health of the woman is not clearly stated, the law seems to allow termination of pregnancy on much broader grounds than most practitioners think and also seems to give room for smart but untrained personnel to engage in dangerous abortion procedures. It is therefore commendable that service protocols and standards are being developed by the Ministry of Health to standardize abortion in the country. However, there is need to spell out the scope of physical and mental health being referred to in the Act for easy implementation. Probably the courts could help in this regard; taking cognisance of the fact that interpretation of laws also depends on constitutional provisions.

Also not clearly stated is the question of who determines whether a pregnancy threatens the life or physical and mental health of a woman. Is it determined by the medical doctor or the patient herself? Can the woman for instance walk into a pub- 
lic hospital and request for such a procedure, based on the fact that in her opinion the pregnancy is injurious to her mental health? What about a school girl who suddenly finds herself pregnant? Could she also request for the procedure based on the fact that the continuance of the pregnancy threatens her mental health because she is not psychologically prepared for it and more so she would drop out of school? The fact that the Ghanaian law does not spell this out presupposes that like any medical treatment the decision could be arrived at by patient and her doctor after adequate counselling as required by section 67 (2) of the criminal code. In judging whether or not abortion could be detrimental to the physical or mental health of the pregnant woman, account should be taken of the woman's actual or reasonably foreseeable environment thus her whole lifestyle, home and relationships should opened up for thorough examination so that right decision could be taken. For a doctor to do this effectively there would be the need for him or her to be trained appropriately depending on the available policy and standards. In other jurisdiction, like the United Kingdom, the law specifies that such a decision must be taken in good faith by two doctors who must issue a certificate of opinion. This approach is good but cannot be easily employed in most developing countries due to lack of trained medical practitioners, particularly in rural settings.

The exceptions for rape and defilement are understandable, especially, since these are violent acts usually committed without the consent of the victim and it is assumed that the victim of such an act would experience psychological distress in carrying the pregnancy and bringing up a child of such a union. With the issue of incest, though many cases reported seek to show lack of consent, there could be situations where consent may be given. But it is clear that since such an act is illegal and abhorred by society, children of such a union may not be accepted and therefore, the choice is given to the woman to decide to have an abortion or not. Rape, defilement, carnal knowledge of a female idiot and incest are all criminal offences under the Ghanaian criminal code. It is worthy to note that the provision covers only defilement of a female idiot but section 101(i) of the Criminal code makes it an offence to defile or have carnal knowledge of any child below sixteen years of age. Such children are capable of becoming pregnant as a result of defilement but have not been covered by the Act. This may be considered a serious omission in the code and needs to be corrected.
These exceptions, however, raise certain questions about the time and abortion is to be performed. Could a medical officer, based on these circumstances go ahead and perform the procedure when the 'victim' reports at the hospital and informs the medical practitioner of the offence and demands an abortion or should the medical officer wait until the guilt of the accused has been established in the court? These questions arise because the accused is usually innocent until proven guilty and moreover some rape charges made are quite unfounded and are made for quite different motives. Rape and defilement cases still take a long time for judgment to be given in our courts. Obviously, if the victim has to wait that long, then the legal provision would be useless because she would have carried the pregnancy beyond the time of safe abortion or to term and might have even delivered the baby before any such verdict is given.

The importance of the law allowing abortion when there is substantial risk that the child to be born may suffer from or later develop a serious physical abnormality or disease is self- evident since nobody is happy about caring for a seriously handicapped child. With the advancement in medicine, pregnancies with foetal deformities that are not compatible with life are terminated after adequate counselling of the parents and such services are available in most hospitals in Ghana. The main problem with implementing this provision is the ability to determine the level of the foetal deformity for which legal abortion is permitted. This bring into fore the ethical dilemmas of prenatal diagnosis and therapeutic abortion. Appropriate policies will address most of the anticipated difficulties in implementing this provision in any future safe abortion programme.

\section{Other restrictions}

The law is very specific about the kind of persons allowed to perform abortion and the place where legal safe abortion could be performed. However the provision 'any other registered medical practitioner' gives the connotation that any medical practitioner is allowed to perform abortion. It is however, well known that not every registered medical practitioner has been trained to perform abortion safely. Such a provision therefore gives protection for untrained medical practitioners to engage in dangerous abortion procedures. Again insistence that only medical practitioners be allowed to carry out termination of pregnancy could hamper availability and accessibility of safe abortion service because in most rural towns and villages where unsafe abortion takes place there are 
no doctors. The South African statute for instance allows abortions before 12 weeks to be done by trained midwives. There is therefore the need to clarify the law and amend this part accordingly so that anyone who engages in abortion should be appropriately trained. Furthermore, the possibility of using medical assistants and midwives could be explored as in the post-abortal programme already in place.

The Act explicitly indicates that in all cases the woman must give her consent. In the event that her consent cannot be readily obtained, then such consent could be given on her behalf by her next of kin or person standing in as her parent. Such consent as stated in the Act (section 14) should be an informed consent and should be given by a female of sound mind and at least sixteen years of age This raises the question whether the law allows parents of minor pregnant girls a veto over the decision to have abortion and should the clinic or the practitioner inform or notify parents of such minors who require abortion. This provision needs further clarification. There is no mention of husband's consent. Thus the act permits the woman to take such decisions without necessarily involving the partner since she is the one directly involved and immediately affected by the pregnancy. Husband's consent may be considered as giving the man a veto over the woman's decision. However in some cases the consent of the husband may be obtained as good clinical practice as in a stable family the loss of a pregnancy has wider effects especially in Africa where the woman tends to be 'under the control' of the husband. The husband's objection, however, would not be valid under the criminal code

\section{CONCLUSION}

The discussion on the law has shown that the Ghanaian legislation has changed from the old position of restriction towards liberalization of abortion. It promotes establishment of safe abortion services by allowing grounds for legal abortion that can be broadly interpreted. Setting no limit of gestational age will allow policy makers to set medically acceptable limits in services delivery protocols and standards. It does not impose any third part authorization and no spousal consent is required, thus allowing the woman to arrive at her own decision with her doctor. Aspects that hamper safe abortion include concerns about the definition, the critical level risk to the woman's health and life at which abortion may be offered and that only medical officers be allowed to perform the procedure.
For clarity there is need for more amendments in the law in order to regulate abortion and to enhance the right of the woman to make a choice on her own. There is also the need to expedite action on development policy and standard guidelines for practitioners.

One may be tempted to argue on moral grounds that liberalizing abortion laws would pave the way for increase in the rate of abortion but data shows that countries with developed access to safe and legal abortion and good contraceptive services have low rate of unsafe abortion whereas in those parts of the world where abortion remains prohibited or restricted, clandestine or illegal abortion remains a serious health problem. It has also been observed that the rate at which women seek abortion is similar for women living in developed and developing countries and that contrary to common belief, legalization of abortion does not necessarily increase abortion rates ${ }^{19}$.

Locating abortion within the broader reproductive health services could therefore be an effective way to improve access and acceptability and also promote the health and welfare of women.

"Most people, including physicians prefer to avoid termination of pregnancy and it is with regret that they may judge it to be the best course, given a woman's circumstances. Some doctors feel that abortion is not permissible whatever the circumstances. Respect for their autonomy means that no doctor (or other members of the medical team) should be expected to advise or perform an abortion against his or her personal conviction. Their careers should not be prejudiced as a result. Such a doctor however has an obligation to refer the woman to a colleague who is not in principle opposed to termination". 20

\section{REFERENCES}

1. Child by Choice Trust. Abortion in Law, History \& Religion. Child by Choice Trust Toronto, Canada M5S 3 A7 (416) 961-1507. [Online]

2. Cook RJ, Dickens BM, Bliss LE. International developments in abortion laws from 1988 to 1998. Am J of Pub Hlth1999; 89(4) : 579586

3. Alan Guttmacher Institute. Sharing Responsibility; Women, Society, and Abortion Worldwide. New York, 1999.

4. World Health Organization. (1998a accessed 
2000, June 16). Address unsafe abortion. World Health Day/Safe Motherhood, 7 April 1998: (WHD 98.10).

5. World Health Organization. Unsafe abortion: Global and regional estimates of incidence of maternal mortality due to unsafe abortion, 3rd edition. World Health Organization, Geneva, 1998

6. World Health Organization (1998b). Unsafe abortion. Safe motherhood fact Sheet: 2000, June 16 [Online].

7. Rahman A, Katzive L and Henshaw SK. A Global Review of Laws on Induced Abortion, 1985-1997. Family planning perspectives June 1998; 24(2,)

8. Lassey A and Wilson JB. Trends in maternal mortality in the Korle-Bu Teaching Hospital, in 1984-1994. Ghana Med J 1998; 32a; 910916.

9. Baiden F, Amponsa-Achiano K, Oduro A, Mensah T, Baiden R. and Hodgson A. Unmet need for essential obstetric services in a rural district in northern Ghana: Complications of unsafe abortions remain a major cause of mortality. Pub Hlth 2006; 120(5): 421-426.

10. IPAS, Carrboro, NC 1997. Abortion Laws into Action: Implementing Legal Reform. Initiat in Reprod Hlth Pol, Jan1997; 2(1)

11. Abortion or miscarriage. Consolidation of Criminal Code of Ghana, 1960. Act 29. Section $58,10^{\text {th }}$ December 1999; 37-38.
12. Ghana Statistical Service and MI. Current Contraceptive usage in Ghana. In Ghana Demography and Health Survey, 1998. GSS and Macro International Inc. Calverton, Maryland, 1999; 43-47.

13. Ampofo DA. The dynamics of induced abortions and the social implications for Ghana. Ghana Med J Dec. 1970: 295- 302.

14. Aboagye B and Akosa AB. An autopsy of maternal deaths. Ghana Med J 2000; 34: 152156.

15. Adanu RMK, Ntumy MN, Tweneboah E. Profile of women with abortion complications in Ghana. Trop Doc, 2005; 35: 139-142.

16. Morhe ESK. Views of doctors on institutionalization of termination of pregnancy in Ghana. Long commentary for FWACS part II examinations. 2006; 281-294.

17. Knight B. Pregnancy and abortion. In Simpson's forensic medicine. $11^{\text {th }}$ edition. Arnold 1997; 15: 113-118.

18. Adanu RMK, and Tweneboah E. reasons fears and emotions behind induced abortions in Accra, Ghana. Research Review NS 20.2 (2004); 1-9.

19. Henshaw SK., Singh S. and Haas Taylor. The Incidence of Abortion Worldwide. Family Planning perspectives. Jan 1999; 25(Suppl).

20. FIGO. Ethical Guidelines Regarding Induced Abortion for Non- Medical Reasons. September, 2002 